\title{
Future Generations of Physician-Scientists?
}

\author{
Fernando Nestor Facio Junior ${ }^{1,2, *}$ \\ ${ }^{1}$ Urology, Medicine School, São Jose Rio Preto (FAMERP), SP \\ ${ }^{2}$ Head of Male Health Outpatient Clinic - FUNFARME, Post-doc in Sexual Medicine, Johns Hopkins Medical School, Baltimore \\ *Corresponding author: fnfacio@yahoo.com.br
}

\begin{abstract}
The teaching policy is that educational institutions should encourage and facilitate research, contributing to the preparation of select minds, familiar with scientific thinking and method, giving professionals of the future the ability to think independently and critically.Hence, in the pursuit of perfection and medical-professional qualification, a new medical-scientist training program should support trainees, residents, and physicians whose work would combine research with clinical care.
\end{abstract}

Keywords: clinical medicine, physician, scientist, research

Cite This Article: Fernando Nestor Facio Junior, "Future Generations of Physician-Scientists?" American Journal of Clinical Medicine Research, vol. 5, no. 2 (2017): 20-21. doi: 10.12691/ajcmr-5-2-2.

If the medical community could leave an important legacy to their patients, it would be to leave them the awareness of everything that time had taught and to improve their practice. They would remember the mistakes that had been made so that they would not be repeated, and would show their ability to choose new more effective and safe routes.

They would mold the new generation of physicians, seeking to sculpt them from the raw marble block like Pieta, the masterpiece of Michelangelo who believed that of all the arts, sculpture was the closest to God. Thus, he freed the figure from the gross marble, transforming and revealing all the potential and strength of his art.

Even today, medical schools in Brazil have as their basic principles, teaching and research, associated with patient care. The first two are the core of the course, and the practical and assistance activities are fundamental for good quality teaching and in the development of ideas and projects for experimental research and applied clinical practice. [1] The teaching policy is that educational institutions should encourage and facilitate research, contributing to the preparation of select minds, familiar with scientific thinking and method, giving professionals of the future the ability to think independently and critically.[1]

Hence, in the pursuit of perfection and medicalprofessional qualification, a new medical-scientist training program should support trainees, residents, and physicians whose work would combine research with clinical care.

This is already being put into practice at the Johns Hopkins Hospital in Baltimore, Maryland, USA. The gynecologist responsible for high-risk pregnancies, Jason Vaught (34 years old) delivered a baby just a few hours ago, and he is now in Robert Brodsky's hematology laboratory, preparing serum for experiments that may help other high-risk pregnant women and their babies. [2]

The doctor-scientist explains how he divides his time between the clinic, where he treats women with high-risk pregnancies and the research laboratory, where he studies hellp syndrome (HELLP stands for Hemolysis (a breakdown of red blood cells), ELevated liver enzymes, and Low Platelet count). He devotes a substantial amount of time, usually about 70 percent, to biomedical research. [2]

"I'm a great doctor of maternal-fetal medicine because of my lab work," he says. "And I'm a better researcher because I understand what's at stake." Jason Vaught, MD.

To encourage more physicians to choose this important and arduous path in the teaching career, Johns Hopkins Medical School created this Medical-Scientist Training Program. To inspire a community of medical-scientists in medical schools in Brazil it would be necessary to help those interested by identifying qualified tutors to assist in carrying out the research. It is necessary to allow access to resources to promote the development of projects, such as travel to conferences, exchange of experiences, help and stimulation within institutions, residents and fellows to help medical-scientists reorganize their clinical practices and thus to make lab time more effective for their research.

Concern about the great shortage of medical-scientists in Brazil and in the world has been expressed since the 1970s. In 2013, the National Institute of Health (NIH) convened a working group to address this problem and in 2014, the "Medical-Scientist Workforce Working Group Report" showed that there are barriers to this career, which includes cuts in funding and lower remuneration compared to working in the clinical practice. [2]

The medical-scientist is the one who, besides bedside visits, performs surgeries, discusses cases and attends in an outpatient clinic. Additionally he develops studies and research projects, unlike the 'pure' or basic researcher, whose work is restricted to the laboratory without contact with the patient. The surgeon or clinician also goes to the laboratory looking for answers to questions and doubts during his daily practice. [1]

It is a 'combined' activity, with clinicians developing clinical practice associated with basic and clinical research having the objective of attending to issues arising from observation during contact with their patients. [3] 
Much of the prestige of medical schools is supported by basic research, which effectively contributes to the development and modification of the medical practice, supporting clinical disciplines, and improving disease differentiation and student training.

According to the report, the number of physician-scientists receiving NIH funding is decreasing. In 2011, the NIH funded less than $2 \%$ of physicians in the United States. [4]

For Johns Hopkins School of Medicine, the doctorscientist is at the heart of the institution. The combination of excellence in patient care and research innovation and collaboration make it a wonderful place for young medical scientists to train and qualify. [2]

In the world, medical scientists are inspiring great advances in medicine. Jonas Salk MD, for example, developed the polio vaccine and Alexander Fleming invented penicillin. Moreover, medical-scientists have a long history at Johns Hopkins, including William Osler, who created modern American medical education, demonstrating that students learned both at the head of the bed and in the laboratory. [2]

Physician-scientist Jason Vaught had no laboratory experience and no intention of becoming a researcher when he arrived at Johns Hopkins in 2013.

Vaught just wanted to know more about hellp syndrome, a potentially fatal condition that affects about $1 \%$ of pregnant women and develops after the 23rd week of pregnancy. [5] The only treatment for hellp syndrome is immediate delivery, which can be dangerous for premature babies. [5]
Brodsky led the development of a test that measures the components of serum, a liquid rich in proteins in the blood. He used the test to diagnose a genetic blood clotting disorder that can occur at any age known as atypical hemolytic-uremic syndrome. Vaught used the same test to study the serum of women with hellp syndrome, finding evidence that both conditions have similar biochemical results and that the outcome might lead to treatments to reduce premature births. [5]

Thus, they expect that these programs will increase the likelihood that doctors will choose careers in scientific research because research makes a big difference between professors, contributing to the training of better qualified physicians and improves patient care.

\section{References}

[1] Rasslan, S. Rev Col. Brasileiro de Cirurgiões. Editorial vol.XXVI, 1999; (5).

[2] Minkove J.F. and Nitkin, K. Guiding the Next Generation of Physician-Scientists at Johns Hopkins; Dome, 2016; 67: (11)1-4.

[3] Csiliag, C; Schor, N. O pesquisador-médico: da academia às parcerias. Rev Ass Med Brasil 1999; 45(2): 152-56.

[4] National Research Council. 2011. Research Training in the Biomedical, Behavioral, and Clinical Research Sciences. Washington, DC: The National Academies Press.

[5] Vaught AJ, Gavriilake E, Hueppchen N, Blakemore K, Yuan X, Seifert SM. Direct evidence of complement activation in HELLP syndrome: A link to atypical hemolytic uremic syndrome. Exp Hematol. 2016; 44(5): 390-8. 